\title{
ARTÍCULOS
}

\section{CULTURIZAR LA NATURALEZA, NATURALIZAR LA CULTURA. LA CONSTRUCCIÓN DE LAS NARRATIVAS PATRIMONIALES*}

\author{
THE CULTURALIZATION OF NATURE, THE NATURALIZATION OF CULTURE. \\ THE CONTRUCTION OF HERITAGE NARRATIVE
}

\author{
Beatriz Santamarina Campos ${ }^{1}$
}

Facultad de C.C Sociales. Universidad de Valencia

Recibido: 15 de diciembre de 2019; Aprobado: 20 de julio de 2020.

\begin{abstract}
Cómo citar este artículo / Citation: Santamarina Campos, Beatriz. 2021. "Culturizar la naturaleza, naturalizar la cultura. La construcción de las narrativas patrimoniales". Disparidades. Revista de Antropología 76(2): e024. doi: <https://doi.org/10.3989/ dra.2021.024>.

RESUMEN: Este artículo pretende ser una reflexión teórica en torno a los procesos de institucionalización y normalización del patrimonio cultural, inmaterial y natural. Desde nuestra perspectiva, los tres dominios patrimoniales nacen y se desarrollan en el mismo contexto sociopolítico, contando con instrumentos y agencias similares. Pero, en sus procesos de edificación y autentificación, se produce una inversión en términos discursivos muy significativa. Si en el llamado patrimonio cultural asistimos a lo que denominamos una culturización de la naturaleza, en el patrimonio inmaterial y natural presenciamos una naturalización de la cultura. Esta inversión, reflejada en prácticas y ficciones diferenciadas, nos permite indagar sobre las lógicas desplegadas por el llamado discurso patrimonial autorizado. A través de las mismas, podemos entender cómo se han ido configurando, a lo largo de los últimos dos siglos, los procesos patrimoniales. Nuestra propuesta pasa por considerar, en primer lugar, que los distintos patrimonios han actuado como instrumentos de dominación edulcorada, al confinar, codificar y asignar campos diferenciados amparados en lo disciplinario. $Y$, en segundo lugar, que esta disección patrimonial jerarquizada permite entender cómo se han conformado las políticas geopatrimoniales globales, a través de potentes instituciones especializadas, productoras de topografías metaculturales.
\end{abstract}

PALABRAS CLAVE: Patrimonio Cultural, Natural e Inmaterial; Autenticidad; Dominación; Poder.

ABSTRACT: The aim of this article is to be a theoretical reflection on the processes of institutionalization and normalization of cultural, intangible and natural heritage. From our perspective, these three heritage domains were born and developed within the same socio-political context, relying on similar instruments and agencies. Nonetheless, there is a significant reversal in discursive terms throughout its building and authentication processes. Whereas in the cultural heritage domain we attend to the culturalization of nature, within the intangible and natural heritage domains we witness a naturalization of culture. This reversal, reflected in differentiated practices and fictions, allows us to inquire about the logics displayed by the so-called authorized heritage discourse. Through them, we can understand how the patrimonial processes have been formed over the last two centuries. Our proposal goes

* Este trabajo se ha desarrollado en el marco del proyecto de investigación "Antropología de la Conservación. Una aproximación comparativa a las genealogías y el desarrollo de los Parques Naturales en España" (PID2019-106291RB-I00/ AEI10.13039/501100011033), financiado por el Ministerio de Ciencia e Innovación y el Programa FEDER.

1 Correo electrónico: Beatriz.Santamarina@uv.es. ORCID iD: <https://orcid.org/0000-0002-4170-7382>. 
on to consider, in the first place, that the different patrimonies have acted as instruments of sweetened domination, by confining, coding and assigning differentiated fields covered by disciplinary matters. And secondly, that this hierarchical heritage dissection allows us to understand how global geopatrimonial policies have been formed, through powerful specialized institutions, producers of metacultural topographies.

KEYWORDS: Cultural, Natural and Intangible Heritage; Authenticity; Domination; Power

\section{INTRODUCCIÓN}

En el siglo XIX aparece, por primera vez en el mundo occidental, el concepto de patrimonio colectivo como un dispositivo aglutinador y vertebrador de una pretendida identidad nacional, marcado por un pasado reinventado e intervenido y por un futuro construido como herencia pública y colectiva. Si bien es cierto que podemos rastrear, en los siglos precedentes, antecedentes claros, como pueden ser la voluntad de transcendencia o el coleccionismo, o instituciones claves para su desarrollo, como los museos o bibliotecas (Iniesta 1994; Ballart 1997; González-Varas 2003), no es menos cierto que el patrimonio, tal y como lo concebimos hoy, es un constructo decimonónico. Su gestación y desarrollo deben vincularse a la llegada de una nueva racionalidad, política, económica y social, asociada a los procesos de transformación del mundo moderno (Choay 1996; Hernández 2002; Poulot 2006). Desde nuestra consideración, los rasgos fundamentales de su definición, sus principios moderadores y sus sentidos prácticos están contenidos en su primera formulación. La temprana división entre los patrimonios cultural, natural e inmaterial y su utilización para producir cartografías patrias, articuladas en una mística ora histórica (museos o monumentos) ora ahistórica (parques naturales o museos costumbristas), nos señalan sus características más relevantes.

Partiremos aquí, por tanto, de la idea de que el patrimonio colectivo es un producto de la modernidad y, a la vez, un productor de modernidad (Harrison 2013). Desde su conformación, las tres formas patrimoniales adoptadas -cultural, natural e inmaterial- encapsulan las máximas de la cimentación moderna: la separación de dominios, la clasificación de formas de saberes y la depuración de espacios epistemológicos (Foucault 1970; Latour 1993; Haraway 1995; Maffesoli 1993 y 1997; Lander 2000; Mignolo 1993, 1995, 2012 y 2013). Y son precisamente estos procesos modernos de disociación, codificación y decantación los que dotarán de sentidos y contenidos a los iniciales programas patrimoniales, delimitando sus campos y transformándose los mismos, como veremos a continuación, en estrategias clave para la articulación y legitimación del nacionalismo, el liberalismo y el capitalismo.

Los monumentos y museos nacionales, los parques nacionales y monumentos naturales y los parques costumbristas y museos rurales, en las tres versiones patrimoniales decimonónicas, constituyen un buen muestrario de los criterios activados para la producción de topografías nacionales. Su compartimentación estanca facilitó la asignación y especialización de los campos, así como una institucionalización, musealización y autentificación paralela, pero diferenciada en forma y contenido. El resultado fue notable. El patrimonio cultural quedó reservado para las formas propias de la definición humanista de cultura (Labadi 2007; Pavone 2008), el patrimonio natural para la descubierta y bautizada como naturaleza prístina (Stevens 1997; Diegues 2000; Descola 2007; Selmi y Hirtzel 2007) y el patrimonio inmaterial -anteriormente denominado folklore- para los saberes populares y los modos de vida subalternos (Velasco 1988; Ortiz García 1994; Iniesta 1994; Hafstein 2011 y 2018; Gómez, 2016). Desde entonces hasta hoy, se han mantenido los tres campos, dotándoles de instrumentos y cuerpos jurídicos como realidades diferenciadas e inmanentes. Las listas de patrimonio mundial de la Unesco, como máxima autoridad global, competente y calificada, así lo reflejan (Schmitt 2009; Askew 2010; Frey, Pamini y Steiner 2013; Meskell 2013; Meskell y Brumann 2015).

Ahora bien, la producción de lo patrimonial es una realidad histórica. Sus formas de activación, lógicas, instituciones y agentes han ido transformándose a lo largo del tiempo, acomodándose a los nuevos contextos de producción (Ariño 2002; Del Mármol y Santamarina 2019). Desde que tomara cuerpo el patrimonio, a finales del XIX y principios del XX, hasta el siglo XXI, hemos asistido a multitud de mudanzas en los objetos y sujetos patrimoniales, en su construcción y concreción. Pero, a pesar de ello, en este artículo, partimos de considerar, desde una 
perspectiva teórica y crítica, cómo la configuración actual de nuestros patrimonios responde a los principios establecidos en la primera modernidad. Y sosteniendo esta idea, entendemos que hoy las jerarquizaciones y taxonomías patrimoniales han sido reforzadas en la hipermodernidad, mostrándose claramente en el mapa de las demarcaciones y distinciones globales. Nuestra hipótesis de partida es que los procesos de producción de los distintos patrimonios son una expresión dulcificada de los regímenes de dominación, tanto externos como internos (intra/extra fronterizos), en el sistema mundo moderno/colonial. La distinta construcción discursiva entre el patrimonio cultural y el patrimonio natural e inmaterial (estos dos últimos colocados en el mismo plano narrativo), responde a una lógica inversa. Si el primero es expresión de la culturalización de la naturaleza, los segundos son manifestaciones de la naturalización de la cultura. El patrimonio cultural se alza como éxito del progreso hegemónico (socioeconómico y político) y garantía del desarrollo de capitales (simbólicos, culturales, sociales y económicos). Frente a él, los patrimonios naturales e inmateriales se presentan, por un lado, como reductos conservadores frente a los riesgos $y$, por otro, como la oportunidad política paternalista para contener las disfunciones y para alimentar el imaginario colonialista (dominación de capitales).

Para ello, en primer lugar, abordamos cómo en la elaboración inicial del constructo patrimonial, las incipientes disciplinas académicas jugaron un papel fundamental para configurar los límites de las formas patrimoniales y para otorgar criterios de autenticidad (verdad) a partir de la elaboración de taxonomías. Nos interesa ver aquí cómo construyeron los distintos mecanismos de autenticidad para las distintas formas patrimoniales. En segundo lugar, reparamos en las narrativas patrimoniales que avalaron los distintos campos disciplinarios. Los argumentarios románticos ayudaron a edificar todo el esqueleto patrimonial. Así, en el plano discursivo es posible observar cómo los criterios de autentificación permitieron la legitimidad del sistema hegemónico a través de un aparato edulcorado. En tercer lugar, atendemos a la institucionalización de los tres campos patrimoniales, viendo su desarrollo paralelo y el papel jugado por cada uno de ellos. En cuarto lugar, analizamos cómo se presenta hoy el patrimonio colectivo, atendiendo a su construcción globalizada bajo la fórmula de Patrimonio de la Humanidad impulsada por la Unesco, para observar cómo, a través de esta agencia especializada, se reproducen las cartografías decimonónicas. Para finalizar, presentamos unas breves conclusiones lanzando una serie de preguntas con el objeto de abrir el debate sobre los procesos patrimonialización en un contexto de hiperinflación, mercantilización y fetichización patrimonial.

\section{LOS PATRIMONIOS Y LOS CAMPOS DISCIPLINARIOS: ORIGEN Y DESARROLLO}

Partiremos de la premisa de que la producción de lo patrimonial es una realidad histórica y relacional, lo que obliga a romper su concepción aislada y permite su aproximación como tecnología de gobierno (Bendix, Eggert y Peselmann 2013; Chaves, Montenegro y Zambrano 2014; Del Mármol 2017; Alonso 2017). El patrimonio colectivo es una categoría acentuadamente política y conflictiva (Smith 2006; Bendix 2009; Franquesa 2013; Roigé y Frigolé 2010; MacDonald 2013; Sánchez-Carretero et al. 2019; Santatamarina y Del Mármol 2020) ratificada en la autenticidad (Jokilehto 2006; Davallon 2010; Frigolé 2014; Del Mármol y Estrada 2018) y su ejercicio comprende "modos de poder y control» (Cruces 1998: 84)

El propio desarrollo de la noción de patrimonio obliga a comprender cómo, en distintos contextos, se privilegian ciertos espacios y conocimientos, vinculados a procesos de construcción hegemónica, a través de numerosas instituciones, prácticas y discursos. Por tanto, rastrear las genealogías de las formas patrimoniales obliga a aproximarse a su institucionalización y normalización. Mecanismos que permiten tanto su edificación, como realidad objetivada, como la asignación de sus sentidos, contenidos y formas (Williams 1980; Bourdieu 1991 y 1998; Comaroff y Comaroff 1991).

Ahora bien, las tecnologías desplegadas para su producción nos derivan a los ámbitos disciplinarios donde lo patrimonial ha cobrado una particular forma y donde las relaciones poder/saber y sus afines verdad/autenticidad se plasman (Smith 2004; Hafstein 2014). Tal y como señala Foucault, cada sociedad tiene su propio regimen de verdad: "that is, the types of discourse which it accepts and makes function as true; the mechanisms and instances which enable one to distinguish true and false statements, the means by which each is sanctioned; 
the techniques and procedures accorded value in the acquisition of truth; the status of those who are charged with saying what counts as true» (1980: 131). Y en la nuestra, la economía política de la verdad está en manos del discurso científico y de las instituciones que la producen y permanece sometida al poder político-económico. En este sentido, la tipificación de las modalidades de conocimiento, en la modernidad, como formas diferenciadas de penetrabilidad a la "verdad» -la producción de verdad-, fue un instrumento central del poder (Haraway 1995) convirtiéndose en una propiedad intrínseca del mismo (Foucault 1970, 1975 y 1980). La exigencia de un cuerpo teórico unitario, capaz de jerarquizar y ordenar para producir conocimiento (verdadero) se constituyó como marca distintiva (erudita) y necesitó al conocimiento local, discontinuo y descalificado, para cobrar sentido (Foucault 1975 y 1980). En el contexto del nuevo régimen político-económico, la epistemología (dominio del conocimiento) y la hermenéutica (dominio de significados) fueron fundamentales, al ser los ejes de producción y asignación de verdad, entendiendo la verdad «as a system of ordered procedures for the production, regulation, distribution, circulation, and operation of statements» (Foucault 1980: 133). La creación de los conocimientos subalternos, la colonialidad del saber y el sistema-mundo moderno/colonial fueros necesarios para el desarrollo del capitalismo moderno y el liberalismo. El eurocentrismo, como patrón de poder global, se presentó tan naturalizado como transcendente (Quijano y Wallerstein 1992; Quijano 2000; Ribeiro y Escobar 2008; Escobar y Restrepo 2010; Mignolo 2012 y 2013). Baste recordar, que «knowledge and aesthetic norms are not universally established by a transcendent subject but are universally established by historical subjects in diverse cultural centers» (Mignolo 2012: 129). Dicho esto, se entenderá la importancia de la producción de las disciplinas en cuanto herramientas de legitimación para la edificación de la realidad o, si se prefiere, en cuanto regímenes de verdad.

Desde el principio de la constitución patrimonial, el saber racional, en forma de saber "técnico», será fuente de objetivación de la realidad y las formas patrimoniales vendrán certificadas por la propia generación de los cuerpos disciplinarios. La discriminación relacional entre el conocimiento académico/disciplinario y el conocimiento subalterno/ sometido, estableció una frontera difusa, pero efectiva, entre procesos analíticos/abstractos (conocimiento científico) y sintéticos/concretos (sentido común). El impulso de las disciplinas científicas, con objetos y métodos diferenciados, entre otros, explican la temprana compartimentación patrimonial y la distinta utilización de lo patrimonial para la cimentación de los proyectos políticos. La necesidad de modular un discurso único y legítimo sobre el territorio, la memoria y la identidad desplegó las activaciones patrimoniales bajo criterios científicos. No es baladí que la aparición de la patrimonialización cultural, natural e inmaterial coincida con el avance de sus correspondientes campos disciplinarios. Ahora bien, no pretendemos aquí hacer una genealogía de las disciplinas. Tan sólo queremos poner de manifiesto que la hegemonía de los discursos científicos y la consolidación de los distintos campos disciplinarios fueron necesarias para la edificación de lo patrimonial. A lo largo de los siglos XVI, XVII y XVIII, el desarrollo moderno de la ciencia, con el racionalismo y el empirismo, y la llustración, con la culminación de una Razón, sentarán las bases para el desarrollo positivista y disciplinario. Con este último asistimos al triunfo incondicional del conocimiento científico como paradigma de la comprensión y la verdad del mundo. $Y$ será entonces, a lo largo del siglo XIX, cuando se desarrolle la institucionalización de los distintos campos disciplinarios. Dicha institucionalización queda reflejada en la aparición de distintas sociedades de carácter científico; en la consolidación de áreas de conocimiento o escuelas universitarias; en la presentación de revistas, publicaciones y congresos especializados; en la manifestación de cuerpos expertos con el despliegue de normativas y reglamentaciones; y en la llegada de perfiles profesionales, visibles en las distintas legislaciones patrimoniales.

Por lo que respecta a los grandes campos patrimoniales, distintas disciplinas jugaron un papel fundamental para su constitución, dotándolos de un esqueleto narrativo y de criterios de autentificación para su activación. En el caso del patrimonio histórico-artístico a lo largo del XIX, serán la Historia, la Arqueología, la Historia del Arte, la Arquitectura y la Restauración-Conservación las que se consolidarán como las áreas científicas encargadas de certificar los valores históricos, artísticos y estéticos del "monumento histórico-artístico», perteneciente al campo de las Bellas Artes. El patrimonio por antonomasia, el denominado patrimonio cultural, quedará circunscrito a las élites y legitimado por la 
producción de la autenticidad. Las obras de Ranke, Winckelmann, Burckhardt, Schliemann, Violletle-Duc y Ruskin, entre otros, contribuyeron a la modulación de los distintos campos académicos. La Historia institucionalizada dotará de una trama organizada a lugares comunes y de memoria, gracias a la objetividad empírica y la neutralidad ideológica. El estudio del pasado como objeto, el reconocimiento de fuentes como textos acríticos y la instauración de una metodología la convertirán en una potente certificadora del patrimonio histórico. Junto a ella, la Arqueología dotará de soporte a las narraciones históricas, con los vestigios materiales contribuyendo a la cimentación y vehiculación del pasado y con la verificabilidad propia otorgada por la materialidad. Ambas jugarán un papel clave al dotar a los proyectos de construcción nacional/colonial y a los objetos patrimoniales de una suerte de continuidad temporal a través de la objetivación del pasado (Peiró 1998 y 2013; Ruiz 1992; Díaz-Andreu 2002 y 2004; Vázquez 2003; Fernández 2011; Moro-Abadia 2012). Por su parte, la Historia del Arte se consolidará como la disciplina de la producción artística frente a la industrial, produciéndose un importante crecimiento del coleccionismo y sentándose las bases del gusto (burgués) a través de la experiencia estética. Además, su trabajo en la disección de la verdadera (original) y la falsa (copia) obra de arte será determinante para la asignación de criterios de autenticidad (Kultermann 1996; Mansfield 2005; Revenga 2005; Oviedo 2016). La disciplina de la Arquitectura, a veces a caballo entre la arqueología, el arte y la restauración, contribuirá por su labor de reconocimiento hacia los valores estéticos, por su reinterpretación (e intervención) del pasado y por la puesta en valor del mismo (Collins 1998; Benevolo 1999; Frampton 2012). Por último, la Restauración-Conservación irá adquiriendo un cuerpo normativo y se especializará en la conservación o reconstrucción, para el futuro, de aquellos elementos distinguidos como contenedores de valores nacionales (Macarrón 1995; Ruiz de Lacanal 1999; Vicente 2012 y 2013). De esta forma, el llamado patrimonio cultural será investido como máxima muestra de alarde civilizatorio y genio creativo para la legitimación de la maquinaria políticoeconómica. Los parámetros de la belleza y la estética serán naturalizados y los mecanismos de distinción se presentarán como cualidades neutrales. Sin embargo, el triunfo de la Cultura, una y dominante, con un sujeto portador bien definido, pasaba por la constitución y dependencia de otros subalternos cosificados (naturaleza y cultura naturalizadas).

En el campo del patrimonio natural, la Ecología, la Geografía, la Biología o la Ingeniería Forestal confluirán para su establecimiento y certificación, siendo las facultadas para visar los valores naturales y estéticos del paisaje como monumentos naturales o parques nacionales. El patrimonio natural se reservará como fuente de pureza nacional para el disfrute de las élites. Durante todo eI XIX, la influencia de los trabajos de Darwin, Wallace, Humboldt, Ritter o Haeckel, marcará la patrimonialización natural que estará dominada por ideas científicas y evolucionistas. La transformación espacial y la revolución en la concepción del tiempo favorecerán la consolidación de las distintas disciplinas. La Biología moderna romperá con las tradiciones anteriores, donde primaban las visiones mecanicistas y estáticas, desenvolviendo una noción dinámica y evolutiva de la naturaleza. Su desarrollo permitirá la aparición de la Ecología y ésta contribuirá a la transformación de la visión dominante de la naturaleza al sacar a relucir las complejas relaciones de los seres vivos en los ecosistemas (Bramwell 1989; Deléage 1991; Drouin 1993). La Geografía moderna definirá su campo y fundamentará sus técnicas (Capel 1980; Grau y López 1984). Al margen del debate sobre su aportación fundamental al nacionalismo y colonialismo (Capel 1977; Milton 1990), lo que nos interesa reseñar es su contribución al descubrimiento del paisaje y las nuevas formas de interrelacionarse con el mismo (Martí-Henneberg 1994; Martínez de Pisón 2000; Ortega 2000; Nogué 2005). Por último, la Ingeniería forestal avanzará en la gestión forestal sostenible, aunque la misma responde más a criterios de racionalización económica de los recursos naturales (Gómez Mendoza 1992). El desarrollo de los primeros movimientos conservacionistas (el ambientalismo decimonónico, el proteccionismo aristocrático o el naturalismo) no se puede explicar sin el despliegue de estas disciplinas (Bramwell 1989; Gómez Mendoza 1992; Vincent 1992). Con la expansión disciplinaria del mundo de lo natural, la naturaleza se constituía en un objeto cosificado y un lugar doméstico de intervención sometido a la cultura. La propia denominación temprana de la patrimonialización de la naturaleza como 'parques nacionales' da idea de la voluntad de establecer límites, así como también del papel jugado en la construcción de lo nacional (Daniels 1993; Casado 1997 y 2010; Ortega 2007; 
García Álvarez 2013; Santamarina 2019). El patrimonio natural será activado como máximo exponente de lo original y lo inmaculado, para la legitimación de los proyectos políticos y la expansión/compensación del capitalismo. La belleza intrínseca de lo natural y su carácter prístino se exhibirán como sus cualidades objetivas (García Álvarez 2009; Casado 2010).

Por último, por lo que respecta al patrimonio inmaterial, en el XIX el Folklore y la Antropología serán las disciplinas acreditadas para la certificación de las costumbres y formas de saber particulares, siendo las encargadas de establecer una nítida diferenciación con otras formas de aprehensión de la realidad y de autenticar los valores inmateriales. A lo largo del XIX, ambas disciplinas definen sus objetos bebiendo de las mismas fuentes -positivismo, darwinismo y specerianismo- y los mismos autores -Tylor, Morgan, Frazer- aunque, poco a poco, irán distanciándose entre ellas. En esta forma patrimonial, es fácil observar la doble disección practicada creando modelos subalternos diferenciables. La concepción humanista permitía ejercitar un orden de primacía en los conocimientos sometidos: los intrafronterizos primero (alta cultura/cultura popular), los transfronterizos después (culturas civilizadas/culturas primitivas). Así, dependiendo de si los marcos de producción estaban dentro o fuera de los patrones occidentales, se establecieron jerarquías y se diferenciaron las disciplinas, contribuyendo bien al nacionalismo o al colonialismo. El Folklore nacerá como un campo de conocimiento específico en relación con los usos, costumbres y tradiciones populares, el «saber popular» (Artes Menores frente a las Bellas Artes). El Ilamado Folk-Lore, término anglosajón atribuido William Thoms² ${ }^{2}$ se reservó para el saber de los saberes del pueblo.

El espíritu de la nación encontraba su origen y sus formas primitivas en el espíritu del pueblo. De ahí que su salvaguardia tuviera un carácter patriótico, porque contenía lo más genuino de la nación (manifestaciones fósiles). En estas representaciones fósiles, originarias y ancestrales, lo popular quedaba circunscrito a la cultura tradicional e iletrada como forma simple primigenia, resultado de la evolución desde la barbarie a la civilización. Su autenticidad se

2 Thoms utilizó por primera vez el término folklore en 1846 , para referirse a los usos, costumbres y tradiciones populares. articulaba en la transmisión oral, en la tradicionalidad y en un sujeto difuso con personalidad (pueblo). El folklorista era el gentleman paternalista, en expresión de Thompson (1989), de los sectores subalternos (Bronner 1984; Ortiz 1986; García Canclini 1987; Velasco 1988 y 1990; Thompson 1989; Ortiz García 1994 y 2002). Por su parte, la Antropología despegaba como la ciencia encargada del estudio de las 'otras culturas'. En sus comienzos evidencia la dependencia cientifista de las teorías evolucionistas y las relaciones de subordinación que se establecieron entre las distintas prácticas culturales. El resultado fue la ideaimagen de la historia de la civilización como una trayectoria que parte de un estado de naturaleza y culmina con el progreso escenificado en el mundo occidental, otorgando sentido a las diferencias entre Europa y no-Europa como diferencias de naturaleza (racial) y no de relaciones de poder (Quijano 2000). Ambos argumentos fueron pilares del eurocentrismo y pueden ser reconocidos en el fundamento del evolucionismo y el dualismo. Con la creación disciplinaria de los saberes subalternos, los 'otros' se edificaban como objetos de conocimiento y como sujetos sometidos a un programa político-económico (nacionalismo y colonialismo/capitalismo). La primera versión del patrimonio inmaterial, el folklore ${ }^{3}$, será activada como exponente de la cultura prístina en la acepción más grotesca. Su belleza radicará en su carácter genuino y en la estética de lo colectivo. Los primeros museos antropológicos y folklóricos, junto con los de artes y tradiciones populares, son buena muestra de esta primera articulación patrimonial (Iniesta 1994 y 2001).

De forma muy sintética, hemos visto cómo los grandes campos patrimoniales encontraron en las distintas disciplinas una legitimación fundamental para su constitución. Por un lado, los dotaron de principios de autentificación para su activación, con criterios objetivables y contrastables amparados en el método científico (neutral y portador de verdad). Este esfuerzo epistemológico muestra una correspondencia estrecha entre los objetos y sujetos establecidos y los potenciales patrimoniables

3 El folklore tiene una doble acepción terminológica que puede llevar a la confusión. El término puede hacer alusión a la ciencia que se encarga de la cultura popular o puede referirse al saber popular mismo (Velasco 1990; Ortiz García 1994). 
y patrimonializadores ${ }^{4}$. Al decir esto queremos subrayar, por un lado, que el carácter político de las activaciones patrimoniales se desvió hacia el campo científico de tal modo que, al quedar en manos de expertos, estos consiguieron desactivar su potencial carácter conflictivo (Santamarina y Beltran 2016). Y, por otro, les facultó de un esqueleto narrativo que, como veremos a continuación, fue entretejido con el Romanticismo.

\section{LOS PATRIMONIOS Y LAS NARRATIVAS ROMÁNTICAS}

Las disciplinas ofrecieron la posibilidad de argumentos legítimos para la configuración de los distintos campos patrimoniales. Junto ellas, el Romanticismo facilitó tramas dotando a las narrativas de atractivos argumentarios. Este movimiento, desarrollado con fuerza a partir de la primera mitad del XIX, supuso una crítica a la visión racionalista y empirista ilustrada, con una exaltación del liberalismo y el nacionalismo, del subjetivismo y el individualismo. La tradición, la imaginación, el sentimiento y la religión fueron reclamados como naturales y positivistas frente a la razón y la observación (Zeitlin 1986). Las revoluciones políticas, sociales, económicas y tecnológicas habían trastocado el viejo orden. De tal modo que las transformaciones modernas provocaron una toma de conciencia frente al patrimonio colectivo y un compromiso para su conservación (Choay 1996; Hernàndez et al. 2005). La necesidad de amarres, ante los procesos de aceleración/destrucción modernos, fue clave para la injerencia y modelación selectiva de la evocación y la nostalgia (Hobsbawm y Ranger 1988; Lowenthal 1998). En esa mirada hacia atrás, el pasado se restituirá como fuente de referentes identitarios y como base para la construcción de las distintas formas patrimoniales. Las pinturas, las obras literarias y los libros de viaje románticos contribuyeron de manera activa a descubrir los paisajes, los monumentos histórico-artísticos y el folklore (Martí-Henneberg 1990; González-Varas 2003; Mayral 2003; Martínez Pisón 2004). No es extraño que de la escuela romántica surjan los primeros movimientos y asociaciones para la conservación de las distintas formas patrimoniales. Pensemos, por dar tan sólo un ejemplo, que la

4 La relación entre las disciplinas y el patrimonio ha sido discutida por distintos autores. Ver, entre otros, Vázquez (2003) o Smith (2004). primera reserva natural europea fue impulsada por un grupo de pintores románticos a mediados del XIX (Riechmann 2000) o que la denominación de parque nacional en EEUU fue propuesta por George Catlin ${ }^{5}$, un pintor romántico (Nash 1970; Runte 1977).

La búsqueda de elementos comunes, que determinarán los rasgos o el alma de una nación, englobó todas las esferas socioculturales y propició nuevas narrativas, fundamentales para la construcción patrimonial (Hubeñak 1985; Gellner 1988; Nadal 1990; Daniels 1993; Gillis 1996; Perpinya 2012). El romanticismo impulsó el nacionalismo, el pannacionalismo y el colonialismo a través de la épica, la mística y el esencialismo, vertebrando distintas identidades. Esas identidades, comunidades imaginadas, líquidas o fragmentadas (Anderson 1983; Hall 2003 y 2010; Bauman 2004), necesitaron del aparato patrimonial y sus instituciones para ser representadas (Prats 1997; Poulot 2006; Hernàndez et al. 2005), de tal forma que los dispositivos patrimoniales fueron instituidos como portadores identitarios y marcadores de un lugar común imaginado y proyectado (Daniels 1993; Choay 1996; Gillis 1996). En este sentido, los museos vivirán en el XIX su expansión, presentando distintas versiones identitarias (Iniesta 1994; Harrison 1997).

La conciencia del yo, la primacía del genio creativo, la originalidad y la nostalgia de paraísos perdidos contribuyeron activamente en la construcción de los relatos. El escapismo y el historicismo romántico, su búsqueda idealizada del pasado ante la angustia del presente, será una aportación fundamental para lo patrimonial. Por un lado, al transformar las relaciones con el pasado y, por otro, al crear vínculos emotivos con la historia. Los elementos patrimoniales se convirtieron en importantes vehículos del tiempo, vinculando el pasado con el presente. A los valores históricos, arqueológicos, folklóricos o naturales objetivados por las distintas disciplinas, los románticos sumaron los valores ideológicos y espirituales, en una influencia mutua que deja al descubierto la naturaleza constitutivamente social de la ciencia (Woolgar 1991). Y esa mirada al pasado, atravesada por la idealización de lo medieval, de la naturaleza y de lo rural, dotaría al aparato patrimonial de los elementos necesarios para su edificación. El sentimiento romántico de

5 Para una aproximación a la obra de Catlin como etnografía se puede acudir a López (2005). 
la naturaleza, la experiencia estética del paisaje, generó una idealización de lo natural y lo rural, articulada, en gran medida, en la confrontación entre el mundo natural/rural y el mundo urbano/fabril. La representación se caracterizó por la añoranza del pasado, por la recuperación de aspectos espirituales y por la crítica al menosprecio y la desvalorización de lo natural y lo rural. La ficción del pasado y la esencia cultural/natural idealizada se fundieron en lo patrimonial como logro colectivo y refugio ante los cambios experimentados provocados por la primera modernidad (Anderson 1983; Hobsbawm y Ranger 1988; Thompson 1988; Lowenthal 1998). En el romanticismo se plasman no sólo las contradicciones de un mundo en transición, sino también el acenso del poder de la burguesía, confiriendo al liberalismo y el nacionalismo de un movimiento cultural que les ofrecían, a través de la creatividad -literaria, musical y pictórica-, sus bases socioculturales. Junto a la «verdad objetiva» del desarrollo disciplinario, que permitía la certificación de los objetos y las taxonomías, la idea de "la belleza es verdad» ${ }^{6}$ del romanticismo otorgaba una suerte de simbiosis en la construcción patrimonial. El transvase de criterios entre ambos serviría para construir puentes y para facilitar la construcción de un discurso hegemónico sobre los campos patrimoniales. Veamos ahora cómo se tejieron ambos, contribuyendo a la compartimentación patrimonial a partir de argumentaciones polares.

En el caso del patrimonio cultural, la Cultura, una, única e indivisible, encapsulada en el monumento histórico-artístico, se presentó como la superación de la condición natural. La distinción era creativa en un doble sentido. La capacidad de crear del ser humano permitía vencer los límites de la naturaleza y superarlos. El recién estrenado mundo industrial rompía las ataduras de lo natural, garantizando una producción sin límites y desligándose del espacio y el tiempo (Giddens 1991). El genio creativo, mezcla de inteligencia, conocimiento, talento y gusto, era capaz de alcanzar logros inimaginables y universales. El patrimonio cultural era definido por oposición o lejanía a la naturaleza, expresión máxima de la culturización de la naturaleza. En el imaginario representará el triunfo de la civilización y la señal indiscutible de la

6 Frase tomada del romántico John Keats, poeta británico, de su obra Oda sobre una urna griega (1819), donde se decía: "La belleza es verdad y la verdad es belleza». supremacía de capitales. El patrimonio cultural y sus instituciones afines se reservaron para los gustos y capitales burgueses (García Canclini 1993; Bourdieu 1998). Los espacios patrimoniales, a través de los usos políticos y sociales de la epistemología, se constituían como un instrumento más (el estético) de validación de prácticas autoritarias.

Por su parte, el patrimonio natural y el patrimonio inmaterial compartieron desde el principio una narrativa similar. En ambos casos la construcción fue análoga e inversa a lo experimentado en el patrimonio cultural. Lo natural y el folklore fueron sometidos a un proceso de naturalización basado en su aproximación al mundo de la conceptualizada naturaleza (naturalización de la cultura). La idealización de la naturaleza y del mundo rural, y la necesidad de su conservación para la mitigación de riesgos, se moduló sobre la nostalgia de un pretendido pasado perdido. Las dualidades entre lo urbano y lo rural, y entre lo natural y lo industrial, se conformarían pronto como un poderoso imaginario social donde lo natural evocaba a lo auténtico y lo puro. En este sentido, la construcción de una naturaleza prístina, el anhelado paraíso perdido (el Edén extraviado), fue la encapsuladora de este primer movimiento protector que ambicionaba salvaguardar la «naturaleza salvaje» de la mano y la capacidad destructora del ser humano (Diegues 2000; Hutton, Adams y Murombedzi 2005; Igoe 2006; Descola 2007). Su autenticidad se desprendía de su cercanía a la naturaleza: cuanto más cerca, más auténtico era el objeto patrimonial. En el caso de la naturaleza, la distancia (real y simbólica) y la negación (borrado de la huella humana) funcionaron como mecanismos de activación (Stevens 1997; West, Igoe y Brockington 2006). El imperio de la verticalidad primó en las primeras activaciones del patrimonio natural. La lógica era sencilla: cuanto más alejado de la mano del ser humano, más natural era su dominio (Martínez de Pisón 2000 y 2004; Santamarina 2016). El otro argumento favorecía la expulsión de los nativos (y el control estatal) al presumirse de contener una naturaleza inmaculada. Y si la producción de la naturaleza es una realidad histórica (Smith 2007), lo mismo sucede con el folklore. $Y$ en este también la distancia jugó un papel destacado. De un lado, la real (física), al encontrarse ubicado en las zonas rurales, alejado de las grandes transformaciones y del mundo industrial, en un entorno considerado, en sí mismo, como natural (no contaminado). De otra, la simbólica, al tratarse de conocimientos groseros de la realidad, 
sin fundamento, rústicos y salvajes. Además, su naturalización se acentuaba en el mundo rural por contagio metonímico con el medio ${ }^{7}$. El folklore fue considerado como un producto natural y el Estado lo naturalizó pronto, creándose los primeros parques/ museos costumbristas in situ (Velasco 1990; González Alcantud 2003; Dubé 2004; Aldridge 2004 y 2005; Bortolotto 2011a y 2011b; Hafstein 2011).

En origen, la construcción de lo natural y lo folklórico estuvo tan atravesada por una mirada política paternalista y protectora como por una relación de subordinación. Los criterios científicos utilizados para sus (re)conocimientos provocaron la objetivación, posibilitando su posterior intervención. La naturaleza y el folklore no dejaban de ser productos naturales (salvajes), naturalizados. Frente a ellos, la Cultura (una y única) era reconocida como portadora de valores universales, signo de distinción y alarde civilizatorio, lo que la situaba en una posición de superioridad para intervenir sobre los otros sujetos objetivados. Con las distinciones establecidas (entre la cultura y la naturaleza, entre tipos de conocimientos) se consiguieron dos efectos fundamentales: la cosificación y objetivación de realidades, destinada a su posterior tasación/confiscación, y la legitimación, dirigida a la intervención paternalista de los dominios naturalizados (los patrimonios natural e inmaterial) a raíz de la superioridad del dominio cultural, encapsulada en el genio creativo (patrimonio cultural). Esta distinción permitía respaldar con facilidad la relación subordinada y asimétrica de la naturaleza y la cultura 'popular' frente a la Cultura, en singular y en mayúsculas. El patrimonio histórico-artístico, como metáfora indiscutible del poder, fuente de legitimidad y garante de su reproducción en términos de capitales, se alzará de forma normalizada frente al patrimonio natural e inmaterial. La estética y la cosmética de lo patrimonial, configurada y sacralizada en la verdad, o en la belleza de la verdad, se constituyó entonces como la cara más amable y exquisita del poder.

Por último, como venimos apuntando, el patrimonio colectivo se articuló sobre narrativas temporales y territoriales. Por un lado, necesitó descubrir y proyectar el pasado, reinventándolo e interviniéndolo para su uso normalizado en el control del presente.

7 Más adelante, con la llegada de los ecomuseos, impulsados por Georges-Henri Rivière en Francia, se estrecharán los lazos entre el patrimonio etnológico y la naturaleza (González 2003: 29).
Pero, en esa operación, la memoria y la desmemoria, la rememoración y el olvido, cristalizaron en lecturas unidireccionales y ámbitos diferenciados (Hobsbawm y Ranger 1988; Lowenthal 1998) ${ }^{8}$. La sacralización de la historia en el patrimonio cultural y la negación de la misma en el patrimonio natural e inmaterial respondieron a los intereses del Estado-nación y el capitalismo. La transición del patrimonio privado al patrimonio público no puede entenderse sin estos intereses. Por otro lado, precisó el establecimiento de límites espaciales modulados en pretendidas identidades y comunidades, esencializadas y singularizadas, que permitieran dibujar contornos geopolíticos. Para ambos procesos, las memorias y los territorios entraron en competencia, produciéndose procesos de codificación de ciertos modos culturales (Herzfeld 2004; Smith 2006). El control cronotópico se constituyó como un instrumento cardinal de los distintos proyectos políticos -nacionalistas y colonialistas-borrando disidencias y endulzando inscripciones. En suma, la reificación decimonónica de lo patrimonial como patrimonio sustantivo permitió, en primer lugar, ocultar su carácter estratégico, político e inestable y, en segundo lugar, encubrir a los propios sujetos patrimonializadores.

\section{LA HERENCIA DECIMONÓNICA EN LOS PATRIMONIOS}

En la primera configuración decimonónica se evidencian los mecanismos reguladores que dibujarán décadas más tarde, y en sentido amplio, los mapas geopolíticos patrimoniales. Si en el siglo XIX se definen sus campos y su embrionaria institucionalización, en el $X X$ se producirá su desarrollo con la aparición de numerosa legislación, el reconocimiento de su titularidad social, el cambio del Estado liberal al Estado social y la llegada de múltiples instituciones especializadas (Ballart 1997; Hernández 2002; González-Varas 2003)99. Pero, será a mediados del XX cuando se produzca la aparición de instituciones internacionales para regular sus

8 Esto no niega la posibilidad de otras lecturas contrahegmónicas sobre historias y memorias (Thompson 1979; Wolf 1987; Scott 2003). Para la relación compleja entre memorias y patrimonio se puede ver, entre otros, Viejo-Rose (2015).

9 No podemos extendernos en ello, aunque existe una numerosa bibliografía al respecto, que se ha ido señalando a lo largo del texto. 
ámbitos. Y es aquí donde observamos cómo los tres tomaron caminos diversos, manifestándose en lógicas y tiempos desiguales. La creación de dos organismos supranacionales, la Organización de las Naciones Unidas para la Educación, la Ciencia y la Cultura (UNESCO) en 1946 y la Unión Internacional para la Conservación de la Naturaleza $(\mathrm{UICN})^{10}$ en 1947, marcarán un viraje considerable. Porque ambas, desde su origen, se han constituido como instancias legítimas para la producción de normativa global definiendo las clasificaciones para el gobierno patrimonial. La Unesco nacerá como una agencia experta para la conservación del patrimonio, promoviendo convenios, cartas y recomendaciones, en principio para la protección del patrimonio cultural, inmaterial y natural. Para este último, en alianza con la UICN como administración especializada en la conservación de la naturaleza. La inmensa tarea normativa en lo patrimonial se manifiesta en la instrucción y prescripción de patrones cognitivos y puede verse encapsulada en el establecimiento de criterios internacionales (categorías de bienes en base a criterios jurídicos o disciplinares) y en la aparición del Patrimonio Mundial.

Nos detendremos en este último en cuanto nos permite observar cómo se reproducen y refuerzan las lógicas y las distinciones decimonónicas. Podemos decir que, con la entrada del Patrimonio Mundial, la Unesco mostraba su particular versión de la globalización, mutando la concepción clásica patrimonial vinculada al Estado-nación y apareciendo, por primera vez, la metacultura y, parafraseando a Kirshenblatt-Gimblett, la metanaturaleza en un ejercicio de translocalización y recontextualización (Kirshenblatt-Gimblett 2004). La Convención sobre la Protección del Patrimonio Mundial, Cultural y Natural (París, 1972) sentó las bases de su política estableciendo la existencia de bienes con «valor excepcional universal» (artículo 1) que debían ser conservados porque eran patrimonio común de la humanidad. A la hora de definir los bienes culturales y naturales utilizó un patrón similar. El trabajo normativo realizado para clasificar y ordenar dicho patrimonio como mundial reforzó la dicotomía

10 En origen denominada Unión Internacional para la Protección de la Naturaleza. Cambia su nombre en 1956. La UICN se presenta hoy como el organismo internacional más importante para la conservación de la naturaleza. naturaleza/cultura y dejó fuera a la cultura popular (lo folklórico). Pese a que la patrimonialización de la cultura, la naturaleza y lo inmaterial habían sido procesos paralelos, la Convención de París olvidaba lo inmaterial codificado hasta el momento como folklórico.

Varios factores pueden explicar esta ausencia. En primer lugar, la Unesco daba primacía a los elementos materialistas y monumentalistas y a la concepción eurocéntrica de lo patrimonial (basada en principios historicistas, occidentalistas y cristianos). Triunfaba así la definición humanista de la cultura reforzada unos años antes en la Carta de Venecia (1964). La Carta representaba la consagración de los criterios de los expertos en materia de restauración y conservación. La profesionalización de disciplinas especializadas en el patrimonio histórico-artístico, bien asentadas y desarrolladas en el campo académico, contribuyó a la visión estrecha del patrimonio colectivo. El discurso patrimonial autorizado certificaba con potestad la autenticidad ${ }^{11}$, olvidando no sólo al patrimonio inmaterial sino también a otras formas de entender el patrimonio colectivo.

En segundo lugar, la institución respaldaba la visión monumentalista de lo natural, reforzando la imagen de wilderness y elevando a modelo la protección norteamericana del XIX como fórmula gubernamental para la conservación a través del discurso hegemónico de la biodiversidad (Escobar 1998; Igoe 2006; Holmes 2011). No es casual que la primera declaración ${ }^{12}$ coincida con parques nacionales ya declarados (Yellowstone, Nahanni, Islas Galápagos y Simien), una tendencia que se consolidará en los años posteriores. Su alianza con la UICN, la preocupación cada vez mayor por las cuestiones medioambientales ${ }^{13}$ y la

11 Las Conferencias de Nara (1994 y 2004) denunciaron el occidentalismo de la Carta de Venecia, cuestionando los criterios de autenticidad. Para una aproximación al debate, ver Bortolotto (2010).

12 En la primera declaratoria de 1978 primaron más los criterios ideológicos que los conservacionistas. Por otra parte, duplicar distinciones a un área protegida dificulta su manejo y cuestiona el sentido de proteger lo que ya está protegido (Santamarina 2016).

13 En este periodo asistiremos a la aparición de numerosa legislación medioambiental, a la proliferación de encuentros internacionales y al aumento de áreas protegidas, junto con una multiplicidad de organismos y comisiones que se dedicaran a la promoción y conservación de la naturaleza. 
transformación de la Ecología ${ }^{14}$ contribuyeron a la definición de los bienes naturales. Baste recordar que cuatro meses antes de la Convención de París, se había celebrado la Cumbre de la Tierra en Estocolmo y antes de la misma se había publicado el libro Los límites del crecimiento elaborado por el Instituto de Tecnología de Massachusetts (MIT) y con una enorme repercusión mundial. Tanto en la Cumbre como en el trabajo del MIT se evidenció la crisis ecológica global y la necesidad de tomar medidas urgentes para frenarla.

$\mathrm{Y}$, en tercer lugar, la Unesco reproducía lo sucedido con el campo de lo folklórico en los países occidentales, dejándolo como algo secundario y circunscrito a los llamados museos de arte menor, de costumbres o del pueblo. La cultura popular seguía naturalizándose (Bortolotto 2010 y 2011b) y la Antropología, como disciplina, no tenía el peso de otras y estaba centrada en otros objetos, entrando tan sólo en el inventariado del patrimonio etnológico. Si bien se constata a mediados del XX la necesidad de proporcionar herramientas jurídicas internacionales para el patrimonio inmaterial y en la década de los 70 se intenta impulsar el reconocimiento de la cultura popular, no será hasta finales de los 80 cuando esto cuaje. La Recomendación sobre la Salvaguarda de la Cultura Tradicional y Popular (París, 1989) fue el primer esfuerzo por alcanzar un marco normativo y la admisión de que «la cultura tradicional y popular forma parte del patrimonio universal de la humanidad $»^{15}$. De todas formas, su impulso definitivo llegó en los 90, con la creación de la Sección de Patrimonio Cultural Inmaterial (1992), el programa Tesoros Humanos Vivos (1993) y la Consulta Internacional de Expertos sobre la preservación de Espacios Culturales Populares (Marraquech 1997). Su primera versión como patrimonio mundial fue el Programa de Obras Maestras del Patrimonio Oral e Intangible de la Humanidad (1998) para llegar, finalmente, en 2003, a la Convención para la Salvaguarda del Patrimonio Cultural Inmaterial (Aikawa 2004 y 2009; Kurin 2004; Schmitt 2008; Akagawa and Smith 2019). Y no es extraño que su impulso llegara en ese momento, no

14 Para una aproximación a la transformación y consolidación de la ecología, a mitad del $X X$, se puede acudir, entre otros, a Bramwell (1989), Deléage (1991) o Drouin (1993).

15 http://portal.unesco.org/es/ev.phpURL_ID=13141\&URL_ DO=DO_TOPIC\&URL_SECTION=201.html>. sólo por las críticas por su olvido vertidas desde dentro y fuera de la Unesco sino también por la llegada de la economía de los intangibles que situaba lo inmaterial como un bien de consumo de primer orden (Boltanski y Chiapello 2002; Haskel y Westlake 2017).

Por último, y antes de la equiparación de los bienes inmateriales, interesa señalar la dirección de cómo se irían tejiendo los mapas de la Unesco. En la primera década de activación del Patrimonio Mundial, los bienes declarados apuntaban al desequilibrio de sus listas tanto por su ubicación como por el desigual reparto de bienes. Y, por otro lado, comenzaban a indicar dónde y cómo se situaba la Cultura (Europa) y la Naturaleza (América y África) ${ }^{16}$. Del mismo modo, al comienzo de la activación de la lista del patrimonio inmaterial, Asia se erigió como la portadora. A día de hoy, la relación del Patrimonio de la Humanidad sigue presentando un claro desequilibrio: 869 bienes culturales, 203 bienes naturales y 508 bienes inmateriales. De igual manera lo observamos si prestamos atención a su emplazamiento la Unesco proyecta una clara geopolítica de dónde se encuentran los bienes en su distribución geográfica. Atendiendo al número total de bienes declarados, los culturales se concentran en el continente europeo, los naturales destacan en los continentes americano, africano y oceánico y los inmateriales sobresalen en el asiático. Las listas del Patrimonio Mundial pueden leerse como un complejo régimen de gobernanza (Zacharias 2010), pero también como una forma de dominación al conformar una realidad hegemónica global (Askew 2010), reconocida y amparada por la mayoría de los países. Pensemos, además, que "the cultural policies of most of the countries in the world have been profoundly influenced by UNESCO» (Seeger 2015: 279).

\section{CONCLUSIONES}

Los procesos de institucionalización y normalización del patrimonio cultural, inmaterial y natural son complejos y discontinuos. El patrimonio colectivo puede ser leído como un proyecto político e ideológico (Kuutma 2013; Tauschek 2013) y como un dispositivo de dominación benévolo, al lindar y ordenar espacios, definidos y blindados, en los

16 América, el nuevo mundo, y África, el más primitivo, encapsulan la naturaleza auténtica. 
campos disciplinarios (Smith 2006). Y lo hace sobre un terreno donde existe un amplio consenso social, aceptándose como moral normativa la conservación y la salvaguardia ${ }^{17}$. Sus tecnologías de fabricación y certificación del pasado responden a aparatos similares y configuran regímenes patrimoniales donde se plasman las relaciones de poder (Geismar 2015). De ahí, su potencial para la legitimación de las hegemonías y para reforzar la desigualdad de capitales. En la esfera discursiva el patrimonio colectivo se exhibe, bajo dicotomías modernas, en una triada donde podemos observar una inversión significativa entre patrimonios con importantes efectos prácticos y materiales. El patrimonio cultural se presenta como una culturización de la naturaleza y el patrimonio inmaterial y natural como una naturalización de la cultura. Esta inversión, lejos de ser baladí, muestra una jerarquía patrimonial observable tanto en las topografías e imaginarios nacionales, como en las políticas geopatrimoniales poscoloniales y globales. Asimismo, puede traducirse en términos de dominación al cosificar, intervenir y domesticar a los otros subalternos caracterizados por su naturaleza «naturalizada». Esta estrategia epistemológica, ontológica y estética garantiza el éxito del proyecto neoliberal y la apropiación de capitales bajo la manta velada del paternalismo y la protección.

La herencia decimonónica, como hemos podido observar, se ha mantenido hasta nuestros días, mostrando una correlación estrecha entre objetos (patrimoniables) y sujetos (patrimonializadores). De hecho, hoy las clasificaciones patrimoniales se han reforzado, revelándose notoriamente en el mapa de las demarcaciones y distinciones globales. La Unesco se muestra como un eficaz aparato normativo que configura realidades bajo la aparente amabilidad de contribuir al desarrollo, la educación, la sostenibilidad y la igualdad. Pero, tras su aparente bondad, priman unos principios globocéntricos (Coronil 2000) que contribuyen a ratificar las relaciones de dominación. La ideología moderna no sólo continúa vigente, sino que se presenta más radical. Las tecnologías de depuración epistemológicas y las grandes narrativas siguen en vigor, para garantizar los marcos hegemónicos amparados en viejas dualidades; y, con ellos, se asegura la reproducción de un sistema instituido en

17 El postulado es simple y paradójico: hay que proteger nuestro mejor legado para las generaciones venideras por nuestra enorme capacidad destructiva. la desigualdad. Más que posmodernidad cabe hablar de hipermodernidad, porque se han acentuado sus procesos con el neoliberalismo y neocapitalismo, provocando procesos de homogeneización, desterritorialización, reterritorialización e hibridación (Appadurai, 1996; Hernàndez 2004). Las cartografías decimonónicas se replican, transformadas en un contexto de hiperinflación, mercantilización y fetichización patrimonial (Bendix 2009; Heinich 2009; Hafstein 2014), poniendo el acento en las diferencias (a favor de la demanda), frente a la distinción (propia de activación clásica). Hoy, el mercado ha desplazado al Estado en su voluntad patrimonial (Santamarina y Del Mármol 2017).

El capitalismo posfordista, la nueva economía cultural y la filosofía neoliberal (Throsby 2001; Treanor 2005; Anheier y Isar 2008) han convertido al patrimonio colectivo en objeto de transacción económica (Ashworth y Van Der Aa 2006; Brumann 2012; Meskell 2014). Richards (2019) advierte cómo la cultura se ha convertido en el nuevo petróleo y, en este sentido, el patrimonio se ha transformado en el mercado turístico con mayor proyección (Timothy 2018; Espeso 2019). La obstinación por el pasado y la tradición (Bauman 2017; Korstanje 2019) ha provocado la rápida expansión de los regímenes patrimoniales, al proveer los mismos de productos anhelados, auténticos y nostálgicos (Comaroff y Comaroff 2009; Ange y Berliner 2016; Boym 2016; Hafstein 2018).

En este contexto, la Unesco juega un papel fundamental comogeneradorde mercado patrimonial, a través de su potente marca: el Patrimonio Mundial. Desde su creación, ha producido una pugna global por su sello y ha situado el marketing heritage en primera línea (Ryan y Silvanto 2011; Lai y Ooi 2015; Grätzer, Rengard y Terlouw 2015) provocando una ambivalencia entre la protección y la mercantilización (Broude 2018). Esto ha desvirtuado su fin como institución para la conservación y la salvaguardia, convirtiéndose en una agencia para visar la marca patrimonial al servicio del capital. Pero el patrimonio colectivo debe quedar al margen de los intereses político-económicos y de las cartografías turísticas. Su mercadeo genera arduas implicaciones éticas. Su dimensión política y su potencial desconstrucción es una opción y debe abrir vías para transformar las reglas. La espectacularización y banalización de las distintas expresiones culturales, en cualquiera de sus denominaciones, obligan a generar espacios 
de reflexión, escenarios para la discusión que dé sentido a una nueva forma de pensar el conocimiento y el reconocimiento, en esa labor constructora y desconstructora de Otros patrimonios posibles.

\section{BIBLIOGRAFÍA CITADA}

Aikawa, Noriko. 2004. «An Historical Overview of the Preparation of the UNESCO International Convention for the Safeguarding of the Intangible Cultural Heritage». Museum International 56 (1-2): 140-153. doi: <https://doi. org/10.1111/j.1350-0775.2004.00468.x>.

Aikawa, Noriko. 2009. "La Convention de l'Unesco pour la sauvegarde du patrimoine culturel immatériel et sa mise en œuvre» en VVAA. Le patrimoine culturel immatériel à la lumière del'Extrême-Orient: 13-45 París: Maison des cultures du monde Babel.

Aldridge, Don. 2004. «De cómo la nave de la interpretación fue arrojada a la tempestad: Algunos pensamientos filosóficos». Boletín de Interpretación 11: 19-32. Disponible en: <https:// boletin.interpretaciondelpatrimonio.com/index.php/ boletin/article/view/235>.

Aldridge, Don. 2005. «La interpretación como indicador de la convicción cultural». Boletín de Interpretación 12: 11-21. Disponible en: <https://boletin.interpretaciondelpatrimonio. com/index.php/boletin/article/view/220>.

Alonso, Pablo. 2017. El antipatrimonio. Fetichismo y dominación en Maragatería. Madrid: CSIC.

Anderson, Benedict. 1983. Imagined Communities: Reflections on the Origins and Spread of Capitalism. Londres: Verso.

Angé, Oliva y David Berliner (eds.). 2016. Anthropology and Nostalgia. Nueva York: Berghahn.

Anheier, Helmut y Yudhishthir Raj Isar (ed.). 2008. Cultures and globalization: The Cultural Economy. Londres: Sage.

Appadurai, Arjun. 2001. La modernidad desbordada. Dimensiones culturales de la globalización. Buenos Aires: FCE.

Ariño, Antonio. 2002. «La expansión del patrimonio cultural». Revista de Occidente 250: 129-150.

Ashworth, Gregory John and Bart JM van der Aa. 2006. "Strategy and Policy for the World Heritage Convention: Goals, Practices and Future Solutions», en Anna Leask y Alan Fyall (eds.) Managing World Heritage Sites: 147-158. Londres: Elsevier.

Askew, Marc. 2010. "The magic list of global status: UNESCO, World Heritage and the Agendas of States. Heritage and Globalisation», en Sophia Labadi y Colin Long (eds.), Heritage and Globalization: 19-44. Londres: Routledge.

Ballart, Josep. 1997. El patrimonio histórico y arqueológico: Valor y uso. Barcelona: Ariel.

Bauman, Zygmunt. 2004. Identity. Cambridge: Polity Press.

Bauman, Zygmund 2017. Retrotopia. Cambridge: Polity Press.
Bendix, Regina F. 2009. "Heritage between Economy and Politics: An Assessment from the Perspective of Cultural Anthropology", en Laurajane Smith and Natsuko Akagawa (eds.) Intangible Heritage: 253-269. Londres: Routledge.

Bendix, Regina F., Aditya Eggert, y Arnika Peselmann (eds.). 2013. Heritage Regimes and the State. Gotinga: Universitätsverlag Göttingen.

Benevolo, Leonardo.1999. Historia de la arquitectura moderna. Barcelona: Gustavo Gili.

Boltanski, Luc y Ève Chiapello. 2002. El nuevo espíritu del capitalismo. Madrid: Akal.

Bortolotto, Chiara. 2010. «Globalising Intangible Cultural Heritage? Between Internacional Arenas and Local Appropriations». En Sophia Labadi and Colin Long (eds.), Heritage and Globalization: 111-128. Londres: Routledge.

Bortolotto, Chiara (ed.). 2011a. Le patrimoine culturel immatériel : enjeux d'une nouvelle catégorie. París: Éditions de la Maison des sciences de l'homme.

Bortolotto, Chiara. 2011b. «Le trouble du patrimoine culturel immatériel». En Chiara Bortolotto (ed.). Le patrimoine culturel immatériel: enjeux d'une nouvelle catégorie: 2146. París: Éditions de la Maison des sciences de l'homme.

Bourdieu, Pierre. 1991. El sentido práctico. Madrid: Taurus.

Bourdieu, Pierre.1998. La distinción. Criterio y bases sociales del gusto. Madrid: Taurus.

Boym, Svetlana. 2016. El futuro de la nostalgia. Madrid: Antonio Machado Libros.

Bramwell, Anna. 1989. Ecology in the 20 $0^{\text {th }}$ Century. Londres: Yale University Press.

Bronner, Simon J. 1984. «The Early Movements of Anthropology and Their Folkloristic Relationships». Folklore 95(1): 5773. Disponible en: <https://www.tandfonline.com/doi/ pdf/10.1080/0015587X.1984.9716297>.

Broude, Tomer. 2018. "Mapping the Potential Interactions between UNESCO's Intangible Cultural Heritage Regime and World Trade Law». International Journal of Cultural Property 25(4): 419-448.

Brumann, Christoph. 2012. «Multilateral Ethnography: Entering the World Heritage Arena». Max Planck Institute for Social Anthropology, Working Paper 136.

Capel, Horacio. 1977. «Institucionalización de la geografía y estrategias de la comunidad científica de los geógrafos Il». Geo Crítica: cuadernos críticos de geografía humana 8: 3-50.

Capel, Horacio. 1980. "Sobre clasificaciones, paradigmas y cambio conceptual en Geografía». El Basilisco: Revista de materialismo filosófico 11: 4-12.

Casado de Otaola, Santos. 2010. Naturaleza Patria. Ciencia y sentimiento de la naturaleza en la España del regeneracionismo. Madrid: Fundación Jorge Juan-Marcial Pons.

Casado de Otaola, Santos. 1997. Los primeros pasos de la ecología en España. Madrid: Ministerio de Agricultura, pesca y alimentación. 
Chaves, Margarita, Mauricio Montenegro y Marta Zambrano (eds). 2014. El valor del patrimonio: mercado, políticas culturales y agenciamientos sociales. Bogotá: ICAH.

Choay, Françoise. 1996. L'allégorie du patrimoine. París: Seuil.

Collins, Peter. 1998. Los ideales de la arquitectura moderna; su evolución (1750-1950). Barcelona: Gustavo Gili.

Comaroff, John L. and Jean Comaroff. 1991. Of Revelation and Revolution. Chicago: University of Chicago Press.

Comaroff, John L., y Jean Comaroff. 2009. Etnicidad S.A. Madrid: Katz.

Coronil, Fernando. 2000. «Naturaleza del Poscolonialismo: Del Eurocentrismo al Globocentrismo». En Edgardo Lander (ed.), La Colonialidad del Saber: Eurocentrismo y Ciencias Sociales. Perspectivas Latinoamericanas: 23-67. Buenos Aires: CLACSO. Disponible en: <http://bibliotecavirtual. clacso.org.ar/clacso/sur-sur/20100708034410/lander.pdf>.

Cruces, Francisco. 1998. «Problemas en torno a la Restitución del Patrimonio. Una Visión desde la Antropología». Política y Sociedad 27: 77-87.

Daniels, Stephen.1993. Fields of Vision: Landscape Imaginary and National Identity in England and the United States. Princeton, Cal.: Princeton University Press.

Davallon, Jean. 2010. «The Game of Heritagization». En Xavier Roigé y Joan Frigolé (eds.), Constructing Cultural and Natural Heritage. Parks, Museums and Rural Heritage: 2738. Girona: ICRPC.

Del Mármol, Camila. 2017. Pasados locales, políticas globales. Valencia: Neopatria-AVA.

Del Mármol, Camila y Ferran Estrada. 2018. «Naturalizing Culture in the Pyrenees: Heritage Processes in Rural Contexts». En A. Arregui, G. Mackenthun y S. Wodianka (eds), Decolonizing Heritage: Natures, Cultures and the Asymmetries of Memory: 219-236. Münster y Nueva York: Waxmann Verlag.

Del Mármol, Camila y Beatriz Santamarina. 2019. «Seeking Authenticity: Heritage and Value within the Intangible Economy». Journal of Mediterranean Studies 28(2): 117-132.

Deléage, Jean P. 1991. Historia de la ecología. Una ciencia del hombre y de la naturaleza. Barcelona: Icaria.

Descola, Philipe. 2007. «Posface. Les coulisses de la natura» Cahiers d'antropologie sociale 3: 123-127.

Díaz-Andreu, Margarita. 2002. «Archaeological Practice and the Nation-State». Antiquity 76(294): 1140. doi: <https:// doi.org/10.1017/S0003598X00092061>.

Díaz-Andreu, Margarita. 2004. «Nacionalismo y arqueología: el contexto político y nuestra disciplina». Eres. Arqueología/ Bioantropología 12: 143-168. Disponible en: <https:// dialnet.unirioja.es/servlet/articulo?codigo=1408881>.

Diegues, Antonio Carlos S. 2000. El mito moderno de la naturaleza intocada. Quito: Editorial Abya Yala.

Drouin, Jean-Marc. 1993. L'écologie et son histoire. Réinventer la nature. París: Flammarion.
Dubé, Philippe. 2004. "La hermosura de lo vivo o el regreso de lo reprimido», Museum International 221: 125-132.

Escobar, Arturo y Eduardo Restrepo. 2010. Territorios de diferencia: Lugar, movimientos, vida, redes. Colombia: Envión Editores.

Escobar, Arturo. 1998. "Whose Knowledge, Whose Nature? Biodiversity, Conservation, and the Political Ecology of Social Movements». Journal of Political Ecology 5-1: 53-82. Disponible en: <https://journals.uair.arizona.edu/index. php/JPE/article/view/21397>.

Espeso-Molinero, Pilar. 2019. «Tendencias del turismo cultural». Revista Pasos 17-6: 1101-1112. Disponible en: <https://riull.ull.es/xmlui/bitstream/handle/915/17838/ PS_17_6\%20_(2019)_01.pdf >.

Fernández, Víctor. 2011. «Arqueología y hegemonía: la contribución al pensamiento conservador español entre los siglos XIX y XX». Actas de IV Congresso de arqueología Peninsular: 281-289. Portugal: Universidade do Algarve.

Foucault, Michael. [1975]1994. Vigilar y Castigar. Madrid: SXXI.

Foucault, Michael.1970. The Order of Things: An Archaeology of the Human Sciences. Londres: Tavistock.

Foucault, Michel. 1980. Power/knowledge: Selected Interviews and Other Writings, 1972-1977. Nueva York: Pantheon Books.

Frampton, Kenneth. 2012. Historia crítica de la arquitectura moderna. Barcelona: Gustavo Gili.

Franquesa, Jaume. 2013. Urbanismo Neoliberal, Negocio Inmobiliario y Vida Vecinal: El Caso de Palma. Barcelona: Icaria.

Frey, Bruno, Paolo Pamini y Lasse Steiner. 2013. «Explaining the World Heritage List: an Empirical Study». International Review of Economics 60(1): 1-19. doi: <https://doi. org/10.1007/s12232-013-0174-4>.

Frigolé, Joan. 2014. «Retóricas de la autenticidad en el capitalismo avanzado». Endoxa 33: 37-60. Disponible en: <http://revistas.uned.es/index.php/endoxa/article/ view/13564>.

García Álvarez, Jacobo. 2009. «Lugares, paisajes y políticas de memoria: una lectura geográfica» Boletín de la A.G.E. 51: 175-202. Disponible en: <https://bage.age-geografia.es/ ojs//index.php/bage/article/viewFile/1137/1060>.

García Álvarez, Jacobo. 2013. «Paisajes, memoria histórica e identidad nacional en los inicios de la política de conservación de la naturaleza en España: de Covadonga a San Juan de la Peña». Hispania 73 (244): 409-438. Disponible en: <http://hispania.revistas.csic.es/index.php/ hispania/article/view/402>.

García Canclini, Nestor. 1987. «Ni folklórico ni masivo ¿qué es lo popular?». Revista Diálogos de la Comunicación 17: 6-11. Disponible en: <https://ilusionismosocial.org/pluginfile. php/530/mod_resource/content/3/garcia_canclini1.pdf>.

García Canclini, Nestor. 1993. «Los usos sociales del patrimonio cultural». En Enrique Florescano (comp.), El patrimonio cultural de México: 41-62. México: FCE. 
Geismar, Haidy. 2015 «Anthropology and Heritage Regimes». Annual Review of Anthropology 44: 71-85. doi: <https://doi.org/10.1146/annurev-anthro-102214-014217>.

Gellner, Ernest. 1988. Naciones y nacionalismo. Madrid: Alianza Editorial.

Giddens, Anthony. 1991. Consecuencias de la modernidad. Madrid: Alianza Editorial.

Gillis, John (ed.). 1996. Commemorations: The Politics of National Identity. Princeton, Cal.: Princeton University.

Gómez Mendoza, Josefina.1992. Ciencia y política de los montes españoles (1848-1936). Madrid: ICONA.

Gómez, Eloy. 2016. «El patrimonio etnográfico: de patrimonio despreciado a patrimonio valioso». En Miguel Cisneros y Virginia Cuñat (eds.), Patrimonio olvidado, patrimonio recuperado: 45-74. Cantabria: UC.

González Alcantud, José A. 2003. «Patrimonio y pluralidad. El largo camino conjuntivo de la alteridad y la materialidad cultural». En Jóse A. González (ed.) Patrimonio y pluralidad. Nuevas direcciones en Antropología patrimonial: 13-40. Granada: Biblioteca de Etnología.

González-Varas, Ignacio. 2003. Conservación de bienes culturales: teoría, principios y normas. Madrid: Cátedra.

Grätzer, Matus, Martin Rengard y Frank Terlouw. 2015. «The World Heritage as a Brand: Case study of World Heritage Brand Usage by Sites and their Stakeholders in Context of Sweden and Denmark». Linnaeus University: 1-70. Disponible en: <http://www.diva-portal.org/smash/get/ diva2:821916/FULLTEXT01.pdf>.

Grau, Ramón y Marina López. 1984. «Para un esquema histórico del pensamiento geográfico». Revista de Geografia 18(1): 19-29.

Hafstein, Valdimar Tr. 2011. «Célébrer les différences, renforcer la conformité». En Chiara Bortolotto (dir.), Le patrimoine culturel immatériel: enjeux d'une nouvelle catégorie: 75-97. París: Maison des sciences de l'homme.

Hafstein, Valdimar 2014. «Protection as Dispossession: Government in the Vernacular». En Deborah Kapchan (ed.), Cultural Heritage in Transit: Intangible Rights as Human Rights: 25-57. Philadelphia: University of Pennsylvania Press.

Hafstein, Vladimir. 2018. Making Intangible Heritage. El Condor Pasa and other Stories from Unesco. Indiana University Press.

Hall, Stuart. 2003. "Who Needs 'Identity'?». En Hall Stuart y Paul Du Gay (eds.), Questions of Cultural Identity: 1-17. London: Sage.

Hall, Stuart. 2010. «Identidad cultural y diáspora». En Eduardo Restrepo, Catherine Walsh y Víctor Vich (eds.), Sin garantias: Trayectorias y problemáticas en estudios culturales: 349361. Popoyán: Envión editores.

Haraway, Donna J.1995. Ciencia, cyborgs y mujeres. La reinvención de la naturaleza. Madrid: Cátedra.

Harrison, Julia. 1997. «Museums as Agencies of Neocolonialism in a Postmodern World». Studies in Cultures, Organizations and Societies 3(1): 41-65.
Harrison, Rodney. 2013. Heritage: Critical Approaches. Londres: Routledge.

Haskel, Jonathan and Stian Westlake. 2017. Capitalism without Capital. The Rise of the Intangible Economy. Princeton, Cal.: Princeton University Press.

Heinich, Nathalie. 2009. La fabrique du patrimoine. De la cathédrale à la petite cuillère. París: Maison des Sciences de l'Homme.

Hernández, Francisca. 2002. El patrimonio cultural: la memoria recuperada. Gijón: Trea.

Hernàndez, Gil M. 2004. «La desterritorialització del patrimoni cultural en la modernitat globalitzada». El contemporani: revista d'història 30: 41-47.

Hernàndez, Gil M., Beatriz Santamarina, Albert Moncusí, y María Albert. 2005. La memoria construida. Patrimonio cultural y modernidad. Valencia: Tirant Lo Blanch.

Herzfeld, Michael. 2004. The Body Impolitic: Artisans and Artifice in the Global Hierarchy of Value. Chicago: University of Chicago Press.

Hobsbawm, Eric y Terence Ranger. 1988. L'invent de la tradició. Vic: Eumo.

Holmes, George. 2011. "Conservation's Friends in High Places: Neoliberalism, Networks, and the Transnational Conservation Elite». Global Environmental Politics 11(4): 1-21. Disponible en: <http://eprints.whiterose. ac.uk/76972/1/Holmes\%2811\%29GlobalElites.pdf>.

Hubeñak, Florencio. 1985. «El romanticismo político». Revista de Historia Contemporánea 4: 151-166. Disponible en: <https:// idus.us.es/xmlui/bitstream/handle/11441/64688/El\%20 romanticismo\%20pol\%C3\%ADtico\%20N4.pdf?sequence $=1>$,

Hutton, Jon, William Adams y James C. Murombedzi 2005. «Back to the Barriers? Changing Narratives in Biodiversity Conservation». Forum for Development Studies 2: 341-370. doi: <https://doi.org/10.1080/0 8039410.2005.9666319>.

Igoe, Jim. 2006. "Measuring the Costs and Benefits of Conservation to Local Communities». Journal of Ecological Anthropology 10: 72-77. Disponible en: <https://scholarcommons.usf.edu/cgi/viewcontent. cgi?article $=1051 \&$ context=jea $>$.

Iniesta, Montserrat.1994. Els gabinets del món. Antropologia, museus i museologies. Lleida: Pagès Editors.

Iniesta, Montserrat. 2001. "Historias y museos». Cuaderno Central 55: 25-29.

Jokilehto, Jukka. 2006. «Considerations on Authenticity and Integrity in World Heritage Context». City \& Time 2(1): 1-16.

Kirshenblatt-Gimblett, Barbara. 2004. «Intangible Heritage as Metacultural Production», Museum International 56(1-2): 52-65. doi: <https://doi.org/10.1111/muse.12070>.

Korstanje, Maximiliano E. 2019. «Lo no-patrimoniable es invisible a la vista: la obsesión moderna por el Patrimonio Turístico». El periplo sustentable 36: 432-446.

Kultermann, Udo. 1996. Historia de la Historia del Arte: El Camino de una Ciencia. Madrid: Akal Ediciones. 
Kurin, Richard. 2004. "Safeguarding Intangible Cultural Heritage in the 2003 UNESCO Convention: a Critical Appraisal». Museum International 56 (1-2): 68-81. doi: <https://doi.org/10.1111/j.1350-0775.2004.00459.x>.

Kuutma, Kristin. 2013, «Between Arbitration and Engineering: Concepts and Contingencies in the Shaping of Heritage Regimes». En Regina Bendix, Aditya Eggert y Amika Peselmann (eds.), Heritage Regimes and the State: 21-36. Göttingen: Universitätsverlag Göttingen.

Labadi, Sophia. 2007. «Representations of the Nation and Cultural Diversity in Discourses on World Heritage». Journal of Social Archaeology 7 (2): 147-170.

Lai, Shevren y Can-Seng Ooi. 2015. «Branded as a World Heritage city: The politics afterwards». Place Branding and Public Diplomacy, 11 (4): 276-292.

Lander, Edgardo (ed.). 2000. La colonialidad del saber: eurocentrismo y ciencias sociales. Buenos Aires: CLACSO.

Latour, Bruno.1993. Nunca hemos sido modernos. Ensayo de antropología simétrica. Madrid: Debate.

López, Hassan. 2005. "Alcance y límites de la pintura de George Catlin como una etnografía de los indios de Norteamérica». Thémata 35: 695-703. Disponible en: <https://idus.us.es/xmlui/bitstream/handle/11441/27740/ file_1.pdf?sequence=1>.

Lowenthal, David. 1998. El pasado es un país extraño. Barcelona: Akal.

Macarrón, Ana María. 1995. Historia de la conservación y la restauración: desde la antigüedad hasta finales del siglo $X I X$. Madrid:Tecnos.

MacDonald, Sharon. 2013. Memorylands. Heritage and Identity in Europe Today. Londres: Routledge.

Maffesoli, Michel. 1993. El conocimiento ordinario. Compendio de sociología. México: FCE.

Maffesoli, Michel. 1997. Elogio de la razón sensible. Una visión intuitiva del mundo contemporáneo. Barcelona: Paidós.

Mansfield, Elizabeth (Ed.). 2005. Art History and Its Institutions: The Nineteenth Century. Londres: Routledge.

Martí-Henneberg, Jordi M. 1990. «Els Alpinistes i la muntanya: La literatura de muntanya a Suïssa Romanya i a Catalunya en el segle XIX». Treballs de la Societat Catalana de Geografia 65-73. Disponible en: <https:// repositori.udl.cat/handle/10459.1/17383>.

Martí-Henneberg, Jordi. 1994. L'excursionisme científic i la seva contribució a les ciències naturals i a la geografia. Barcelona: Alta Fulla.

Martínez de Pisón, Eduardo. 2000. «Imagen de la naturaleza de las montañas». En Eduardo Martínez de Pisón y Carlos Sanz Herräiz (Eds), Estudios sobre el paisaje: 15-53. Madrid: UAM y Fundación Duques de Soria.

Martínez de Pisón, Eduardo. 2004. «El paisaje de montaña». En Nicolás Ortega (ed.), Naturaleza y cultura del paisaje: 15-54. Madrid: UAM y Fundación Duques de Soria.
Mayral, Gaspar. 2003. «El patrimonio como versión autorizada del pasado». En José A. González (ed) Patrimonio y pluralidad. Nuevas direcciones en Antropología patrimonial: 63-78. Granada: Biblioteca de Etnología.

Meskell, Lynn. 2013. «UNESCO's World Heritage Convention at 40: Challenging the Economic and Political Order of International Heritage Conservation». Current Anthropology 54(4): 483494. doi: <https://doi.org/10.1086/671136>.

Meskell, Lynn. 2014. "States of Conservation: Protection, Politics, and Pacting within UNESCO's World Heritage Committee». Anthropological Quarterly 87(1): 217-243. Disponible en: <http://www.jstor.org/stable/43652726>.

Meskell, Lynn and Christoph Brumann. 2015. «UNESCO and new World Orders». En Lynn Meskell (ed.) Global Heritage: A Reader: 22-42. Malden: John Wiley \& Sons.

Mignolo Walter. 2012. Local Histories/Global Designs: Coloniality, Subaltern Knowledges, and Border Thinking. Princeton, Cal.: Princeton University.

Mignolo, Walter D. 1993. «Colonial and Postcolonial Discourse: Cultural Critique or Academic Colonialism?». Latin American Research Review 28(3): 120-134.

Mignolo, Walter D. 1995. "La razón postcolonial: herencias coloniales y teorías postcoloniales». Revista chilena de literatura 47: 91-114. Disponible en: <https:// revistaestudiosarabes.uchile.cl/index.php/RCL/article/ view/39564/41158>.

Mignolo, Walter. 2013. «Geopolítica de la sensibilidad y del conocimiento. Sobre (de) colonialidad, pensamiento fronterizo y desobediencia epistémica». Revista de filosofía 74: 7-24.

Milton, Santos. 1990. Por una Geografía Nueva. Madrid: Espasa Calpe.

Moro-Abadia, Oscar. 2012. «La nueva historia de la arqueología: Un balance crítico». Complutum 23(2): 177-190. Disponible en: <https://core.ac.uk/download/pdf/38829053.pdf>

Nadal, Francesc. 1990. «Los nacionalismos y la geografía». Geo Crítica: cuadernos críticos de geografía humana 86: 3-45. Disponible en: <http://www.ub.edu/geocrit/geo86.htm>.

Nash, Roderick. 1970. "The American Invention of National Park». American Quarterly 22(3): 726-735. doi: <https://doi. org $/ 10.2307 / 2711623>$.

Nogué, Joan. 2005. «Nacionalismo, territorio y paisaje en Cataluña». En Nicolás Ortega (ed.), Paisaje, memoria histórica e identidad nacional: 146-169. Madrid: UAM y Fundación Duques de Soria.

Ortega, Nicolás. 2000. «Las raíces culturales en la conservación de los paisajes». En Eduardo Martínez de Pisón y Carlos Sanz Herräiz (eds), Estudios sobre el paisaje: 237-258. Madrid: UAM y Fundación Duques de Soria.

Ortega, Nicolás. 2007. «El significado cultural del Parque Nacional del Guadarrama». En Eduardo Martínez de Pisón y Carlos Sanz Herräiz (eds), La conservación del paisaje en los Parques Nacionales: 65-98. Madrid: UAM y Fundación Duques de Soria. 
Ortiz García, Carmen 1994. «Antropología y folklore». Revista de dialectología y tradiciones populares 49(2):49-68. Disponible en: <https://digital.csic.es/handle/10261/44121>.

Ortiz García, Carmen. 2002. «Patrimonio cultural y antropología». Arevacon 21: 5-9. Disponible en: <https:// digital.csic.es/bitstream/10261/36762/2/Patrimonio\%20 cultural\%20y\%20antropolog\%C3\%ADa.pdf>.

Ortiz, Renato. 1986. Notas históricas sobre o conceito de cultura popular. Working Paper $N^{\circ}$. 80. Notre Dame: Helen Kellogg Institute for International Studies, University of Notre Dame. Disponible en: <http://148.202.167.116:8080/ jspui/handle/123456789/2228>.

Oviedo, Mauricio. 2016. "La historia del arte como ciencia: La inserción de Imre Lakatos en la definición de la disciplina». Revista de Filosofía 41(1): 135-152. doi: <https:// doi.org/10.5209/rev_RESF.2016.v41.n1.52111>.

Pavone, Vicenzo. 2008. From the Labyrinth of the World to the Paradise of the Heart: Science and Humanism in UNESCO's Approach to Globalization. Nueva York: Lexington.

Peiró, Ignacio. 1998. «La historiografía académica en la España del siglo XIX». Memoria y Civilización 1: 165-196. Disponible en: <https://core.ac.uk/download/pdf/83560903.pdf>.

Peiró, Ignacio. 2013. Historiadores En España: Historia De La Historia y Memoria de la Profesión. Zaragoza: UniZar.

Perpinyà, Núria. 2012. «European Romantic Perception of the Middle Ages: Nationalism and the Picturesque». Imago Temporis. Medium Aeum 6: 23-47.

Poulot, Dominique. 2006. Une histoire du patrimoine en Occident, XVIII-XIX siècle. Du monuments aux valeurs. París: Presses Universitaires de France.

Prats, Llorenc. 1997. Antropología y patrimonio. Barcelona: Ariel.

Quijano, Aníbal y Immanuel Wallerstein. 1992. «Elementos del desarrollo, la Americanidad como concepto o América en el moderno sistema mundial». Rics 134: 583-591.

Quijano, Aníbal. 2000. «Colonialidad del poder, eurocentrismo y América Latina». En Edgardo Lander (comp.), La colonialidad del saber: eurocentrismo y ciencias sociales. Perspectivas Latinoamericanas: 201-246. Buenos Aires: CLACSO.

Revenga, Paula 2005. "Sobre la historia de la historiografía artística». Saberes. Revista de estudios jurídicos, económicos y sociales 3: 1-23. Disponible en: <https://revistas.uax.es/ index.php/saberes/article/view/773>.

Ryan, Jason y Sari Silvanto. 2011. «A Brand for All the Nations: The Development of the World Heritage Brand in Emerging Markets». Marketing Intelligence \& Planning 29(3): 305-318.

Ribeiro, Gustavo Lins y Arturo Escobar. 2008. Antropologías del mundo: transformaciones disciplinarias dentro de sistemas de poder. México: Envión.

Richards, Greg. 2019. "Culture and Tourism: Natural Partners or Reluctant Bedfellows? A Perspective Paper». Tourism Review 75(1): 232-234.
Riechmann, Jorge. 2000. «Aldo Leopold, los orígenes del ecologismo estadounidense y la ética de la tierra». En Aldo Leopold (ed.), Una ética de la tierra: 7-35. Madrid: Catarata.

Roigé, Xavier y Joan Frigolé (eds.). 2010. Constructing Cultural and Natural Heritage. Parks, Museums and Rural Heritage. Girona: Institut Català de Recerca en Patrimoni Cultural.

Ruiz de Lacanal, Maria Dolores. 1999. El conservadorrestaurador de bienes culturales. Historia de la profesión. Madrid: Síntesis.

Ruiz, Pedro. 1992. "La historia como concepto histórico: historia erudita, historia filosófica e historia científica en los siglos XVIII y XIX». Studia Historica-Historia Contemporánea X-XI: 149-162. Disponible en: <http://hdl.handle.net/10366/80043>

Runte, Alfred. 1977. «The National Park Idea: Origins and Paradox of the American Experience». Journal of Forest History 21 (2): 64-75. doi: <https://doi.org/10.2307/3983461>.

Ryan, Jason y Sari Silvanto. 2011. «A Brand for All the Nations: The Development of the World Heritage Brand in Emerging Markets». Marketing Intelligence \& Planning, 29 (3): 305-318.

Sánchez-Carretero, Cristina, José Muñoz, Ana Ruiz y Joan Roura (eds.). 2019. El imperativo de la participación en la gestión patrimonial. Madrid: CSIC.

Santamarina, Beatriz. 2016. «La naturaleza de las naturalezas patrimonializadas. Una aproximación a las formas hegemónicas de representar lo natural». Revista Arxiu d'Etnografia de Catalunya 16: 153-177. Disponible en: <https://revistes.urv. cat/index.php/aec/article/view/1012>.

Santamarina, Beatriz. 2019. «El inicio de la protección de la naturaleza en España. Orígenes y balance de la conservación". Reis 168: 55-72. Disponible en: <http://www. reis.cis.es/REIS/PDF/REIS_168_041569929431081.pdf>.

Santamarina, Beatriz y Oriol Beltran. 2016. "Heritage and Knowledge. Apparatus, Logic and Strategies in the Formation of Heritage». Anthropological Forum 26(4): 397-414. doi: <https://doi.org/10.1080/00664677.2016.1224763>

Santamarina, Beatriz y Camila Del Mármol 2017. "Ciudades creativas y pueblos con encanto: los nuevos procesos patrimoniales del siglo XX|». Revista Disparidares 72(2): 359-377. Disponible en: <http://dra.revistas.csic.es/index. php/dra/article/view/547>.

Santamarina, Beatriz y Camila Del Mármol. 2020. «'Para Algo que era Nuestro... Ahora es de Toda la Humanidad': El Patrimonio Mundial como Expresión de Conflictos». Chungará-Revista de Antropología Chilena 52(1): 161-173. doi: <http://dx.doi. org/10.4067/S0717-73562020005000301>.

Schmitt, Thomas. 2008. «The UNESCO Concept of Safeguarding Intangible Cultural Heritage: its Background and Marrakchi Roots». International Journal of Heritage Studies 14: 95111. doi: <https://doi.org/10.1080/13527250701844019>.

Schmitt, Thomas. 2009. «Global Cultural Governance. DecisionMaking Concerning World Heritage between Politics and Science». En Erdkunde 63(2): 103-121.

Scott, James C. 2003. Los dominados y el arte de la resistencia. México: Gebara. 
Selmi, Adel y Vicent Hirtzel. 2007. "Gouverner la nature» Cahiers d'Antropologie Sociale (3): 9-12.

Seeger, Anthony. 2015. "Understanding UNESCO: A Complex Organization with Many Parts and Many Actors». Journal of Folklore Research: An International Journal of Folklore and Ethnomusicology 52(2-3): 269-280.

Smith, Laurajane. 2004. Archaeological Theory and the Politics of Cultural Heritage. Londres: Routledge.

Smith, Laurajane. 2006. Uses of heritage. Nueva York: Routledge.

Smith, Neil. 2007. "Nature as Accumulation Strategy». Socialist Register: 19-49. Disponible en: <https://socialistregister. com/index.php/srv/article/view/5856/2752>.

Stevens, Stan. 1997. «The legacy of Yellowstone». En Stan Stevens (ed.), Conservation through Cultural Survival: Indigenous People and Protected Areas: 13-32. Washington: Island Press.

Tauschek, Markus. 2013. «The Bureaucratic Texture of National Patrimonial Policies». En Regina Bendix, Aditya Eggert y Amika Peselmann (eds.), Heritage Regimes and the State: 195-212. Göttingen: Universitätsverlag Göttingen.

Thompson, Edwar P. 1979. Tradición, revuelta y consciencia de clase: Estudios sobre la crisis de la sociedad preindustrial. Barcelona: Crítica.

Thompson, Edward P. 1989. «Folklore, antropología e historia social». Historia social 3: 81-102. Disponible en: <https:// www.jstor.org/stable/40340532>.

Thompson, Paul. 1988. La voz del pasado. Historia oral. Valencia: Alfons El Magnànim.

Throsby, David. 2001. Economics and Culture. Cambridge: Cambridge University Press.

Timothy, Dallen J. 2018. "Making Sense of Heritage Tourism: Research Trends in a Maturing Field of Study». Tourism Management Perspectives 25: 177-180.

Treanor, Paul. 2005. Neoliberalism: Origins, Theory, Definition. Disponible en: <http://web.inter.nl.net/users/Paul.Treanor/ neoliberalism.html>
Vázquez, Luis. 2003. El leviatán arqueológico. Antropología de una tradición científica en México. México: CIESAS

Velasco, Honorio. 1988. «El evolucionismo y la evolución del Folklore». Folk-lore andaluz 2: 13-32.

Velasco, Honorio. 1990. «El folklore y sus paradojas». Reis 49: 123-144. doi: <https://doi.org/10.2307/40183432>.

Vicente Rabanaque, Teresa. 2012. El restaurador de obras de arte en España durante los siglos XVIII y XIX. Nacimiento y reconocimiento de una profesión. Valencia: UPV

Vicente Rabanaque, Teresa. 2013. Del restaurador de obras de arte al conservador-restaurador de bienes culturales. La consolidación disciplinar y profesional de la restauración en España (siglos XX-XXI). Valencia: UPV.

Viejo-Rose, Dacia. 2015. "Cultural Heritage and Memory: Untangling the Ties that Bind». Culture \& History Digital Journal 4(2): 1-18. doi: <https://doi.org/10.3989/ chdj.2015.018>

Vincent, Andrew. 1992. Modern Political Ideologies. Oxford: Blackwell.

West, Paige, James Igoe y Dan Brockington. 2006. «Parks and Peoples: The Social Impact of Protected Areas». Annual Review of Anthropology 35: 251-277. doi: <https://doi. org/10.1146/annurev.anthro.35.081705.123308>.

Williams, Raymon.1980. Marxismo y literatura. Península. Barcelona.

Wolf, Eric R. 1987. Europa y la gente sin historia. México: FCE.

Woolgar, Steve. 1991. Ciencia: Abriendo la caja negra. Barcelona: Anthropos.

Zacharias, Diana. 2010. «The UNESCO Regime for the Protection of World Heritage as Prototype of an Autonomy-Gaining International Institution ». En Armin von Bogdandy (ed.) The Exercise of Public Authority by International Institutions: 301-336. Berlin: Springer.

Zeitlin, Irving M. 1986. Ideología y teoría sociológica. Argentina: Amorrortu. 